\title{
Topical administration of mometasone furoate- a combined impedance spectroscopy and in vitro drug diffusion study
}

\begin{abstract}
Mometasone furoate (MF) is a potent steroid for treatment of e.g., eczema and psoriasis. It exerts its function by binding to the glucocorticoid receptors in viable epidermis and dermis. The aim of the current project was to estimate if two clinically equivalent $0.1 \% \mathrm{MF}$ creams, one w/o (A) and one o/w (B) cream, might impose different systemic load, which is related to adverse side effects. We approached this question by combining analysis of drug permeability in flow through cells and membrane perturbation detected by impedance spectroscopy using excised porcine skin as membranes. We also analyzed the amount of drug that accumulates in the membranes following topical application of the two creams. The results show that both creams generate about the same amount of MF in skin, while Cream A generates an order of magnitude higher drug flux through skin. Cream A also caused a twofold increase in the skin dielectric constant (e), which may be attributed to an increased fluidity of the extracellular lipid matrix in the stratum corneum corresponding to a higher skin permeability. No significant change in skin e was seen with cream B. To conclude, Cream B appears to be the safer alternative as it does not seem to perturb the skin and imposes less systemic burden without sacrificing clinical efficacy.
\end{abstract}

Volume I Issue | - 2015

\author{
Anna Runnsjo, ${ }^{1,2}$ Hala Gari, ${ }^{1,2}$ Tautgirdas \\ Ruzgas, ${ }^{1,2}$ Johan Engblom ${ }^{1,2}$ \\ I Faculty of Health and Society, Malmo University, Sweden \\ 2Biofilms - Research Center for Biointerfaces, Malmo University, \\ Sweden
}

Correspondence: Anna Runnsjo, Biomedical Science Faculty of Health and Society and Biofilms - Research Center for Biointerfaces, Malmo University, Sweden, Tel +46 406657768 , Email anna.runnsjo@mah.se

Received: September 30, 2015 | Published: November 17, 2015

Keywords: topical glucocorticoid, in vitro drug diffusion, impedance spectroscopy, mometasone furoate, water-in-oil emulsion, oil-in-water emulsion

Abbreviations: CPE, constant phase element; $\varepsilon$, dielectric constant; $\mathrm{J}_{\mathrm{ss}}$, steady state flux; MF, mometasone furoate; $\mathrm{R}, \mathrm{r}_{\mathrm{e}}$ sistance; $\mathrm{O} / \mathrm{w}$,oil-in-water emulsion; SC,stratum corneum; TGs,topical glucocorticoids; W/o, Water-in-Oil Emulsion

\section{Introduction}

Topical Glucocorticoids (TGs) show vasoconstrictive, antiinflammatory, immunosuppressive and anti-proliferative effects, and are therefore frequently used to treat psoriasis, atopic dermatitis, asthma ${ }^{2-4}$ and chronic rhinitis. ${ }^{3}$ After application to skin, TGs penetrate the stratum corneum and bind to glucocorticoid receptors in viable epidermis and dermis. ${ }^{1,5-7}$

Although TGs have been shown to be efficient in treatment of various skin diseases, their use can result in both local and systemic side effects. Some of the local side effects are skin atrophy, rosacea, and corticoid acne, while the major systemic side effects are hypothalamic-pituitary-adrenal-axis suppression along with diabetes mellitus and hypertension. ${ }^{1,7-9}$ Mometasone furoate (MF) is a potent steroid (according to the European Union classification system) with relatively low risk of systemic side effects. ${ }^{1}$ The low risk of side effects is largely due to the high lipophilicity ( $\operatorname{lgP} 4.5)$, resulting in low solubility in aqueous fluids such as blood. Systemic uptake is further reduced by the ability of MF to degrade in aqueous solvents at $\mathrm{pH}$ values above 4.9. ${ }^{10}$

For topical formulations, factors such as their ability to hydrate the skin, drug solubility, and release rate of the drug can also affect the bioavailability of the steroid and are therefore important to consider. ${ }^{11}$ In this study we evaluate topical application of two different types of MF creams, both containing the same amount of drug (i.e. Elocon ${ }^{\circledR} 0.1 \%$ cream, Merck, Sharp \& Dohme BV, the Netherlands (Cream A) and Ovixan ${ }^{\circledR} 1 \mathrm{mg} / \mathrm{mL}$ cream, Galenica AB,
Malmo, Sweden (Cream B). According to SWEDIS 2007, ${ }^{12}$ Cream A is water-in-oil (w/o) emulsion with white soft paraffin (54wt\%) as the main component of the continuous oil phase. Only $3 w t \%$ of the cream consists of water, and hexylene glycol (12wt\%) is used as co-solvent for MF. In contrast, Cream B is an oil-in-water $(\mathrm{o} / \mathrm{w})$ emulsion with coconut oil $(8 \mathrm{wt} \%)$ dispersed in the continuous aqueous phase. This cream contains approximately $50 \mathrm{wt} \%$ water and propylene glycol $(25 \mathrm{wt} \%)$ is used as a co-solvent for MF. A previously reported clinical study ${ }^{13}$ showed that use of these two different types of formulations gave similar vaso-constrictive properties and equal clinical response

The aim of the current project was to estimate if these two $0.1 \%$ MF creams might differ in systemic load and corresponding risk for adverse effects. We combined impedance spectroscopy and flow through diffusion cells to evaluate barrier perturbation and penetration of MF through excised skin. We also analyzed the amount of drug that accumulates in the membranes following topical application of the two creams. The effects of the creams on the dielectric properties of the skin and possible correlation between the dielectric properties of the skin and the drug penetration rate were investigated. The combination of impedance and penetration measurements also provided further information on potential pathways for MF through skin.

\section{Materials and methods}

\section{Materials}

Cream A, Elocon ${ }^{\circledR} 0.1 \mathrm{wt} \%$ cream (Merck, Sharp \& Dohme BV Haarlem, the Netherlands), was purchased from a local pharmacy and Cream B, Ovixan ${ }^{\circledR} 1 \mathrm{mg} / \mathrm{ml}$ cream (Galenica AB, Malmo, Sweden), was provided by Galenica AB. Citric acid, sodium citrate dihydrate and sodium chloride were obtained from Sigma Aldrich. Ethanol (99.5\%) was purchased from Kemetyl AB (Jordbro, Sweden). Ultrapurified water ( $\rho=18.2 \Omega \mathrm{cm}$; PURELAB UHQ II system; ELGA 
Labwater, High Wycombe, UK) was used for preparation of all aqueous solutions.

\section{Methods}

The experimental design comprised membrane characterization with impedance spectroscopy in Franz diffusion cells immediately before and after (within 10min) the drug (MF) penetration study, which was conducted in flow through cells with sampling every second hour. The formulations were removed from the membranes prior to the second impedance measurement by washing 3 times with water and gently wiping with tissue and cotton swabs. Any drug retained in the membranes after terminating the experiment was extracted and MF was assayed with HPLC-UV. To minimize possible damage to the membranes during transport between the impedance and the penetration equipment, a $12.3 \times 2.6 \mathrm{~mm}$ x-ring, made of Nitrile rubber (Tatringen Tekniska AB, Haninge Sweden), was attached to the dorsal side of the membranes using cyanoacrylate glue (Loctite Super Glue Precision, Henkel Norden AB, Stockholm, Sweden).

\section{Membranes}

Porcine ears were obtained fresh from a local abattoir and stored at $-80^{\circ} \mathrm{C}$ until use. The ears were then thawed at room temperature and rinsed with cold water. Hair was carefully removed from the inner side of the ear with a trimmer and skin membranes were produced with a dermatome (TCM 3000 BL; Nouvag, Goldach, Switzerland) to a thickness of approximately $500 \mu \mathrm{m}$. Before initiating the experiment, the skin was allowed to hydrate for one hour at $32^{\circ} \mathrm{C}$ in the diffusion cells with the dermal side exposed to the receptor media (a mixture of isotonic $20 \mathrm{mM}$ citrate buffer $(\mathrm{pH} 4.5)$ and ethanol $(70: 30 \mathrm{v} / \mathrm{v}))$ and with the stratum corneum side exposed to the ambient air. Silicone membranes with a nominal thickness of $127 \mathrm{~mm}$ were obtained from Specialty Manufacturing Inc. (Michigan, USA) and rinsed with distilled water prior to use.

\section{Impedance spectroscopy}

The membrane impedance spectroscopy set-up comprised a Franz cell (orifice diameter $=9 \mathrm{~mm}, \mathrm{~V}_{\text {receptor }}=6 \mathrm{~mL}$; Permegear Inc, Hellerstown, USA) with four electrodes connected to a potentiostat from Ivium Technologies (Eindhoven, the Netherlands). The electrodes were connected as working electrode $(\mathrm{Pt})$ and sensing electrode $(\mathrm{Ag} / \mathrm{AgCl})$ in the donor chamber and as counter electrode $(\mathrm{Pt})$ and reference electrode $(\mathrm{Ag} / \mathrm{AgCl})$ in the receptor chamber of the Franz cell. For impedance measurements, an alternating voltage of $20 \mathrm{mV}$ amplitude was applied. The system was controlled with Ivium software, which performed a frequency sweep between $1 \mathrm{~Hz}$ and $6 \mathrm{MHz}$ with frequency steps of 5 points per decade ( 35 points in total per scan).

Data from the impedance measurements, $\mathrm{Z}$ of the membranes were modeled as an equivalent circuit consisting of a constant phase element (CPE) in parallel with the resistance of skin, $\mathrm{R}_{\mathrm{s}}$ :

$$
Z=R_{e}+\frac{R_{s}}{1+R_{s} Q(j 2 \pi f)^{\alpha}}
$$

Where $\mathrm{j}$ is the complex number $\sqrt{ }(-1)$, the parameters $\mathrm{Q}$ and $\alpha$ define the $\mathrm{CPE}$, and $\mathrm{R}_{\mathrm{e}}$ is the resistance of the electrolyte. The values of $\alpha$ and $\mathrm{Q}$ for the different experimental conditions are summarized in Tables S1,S2 (supplementary material). The capacitance, C (Equation 2), was calculated by exploiting the power-law formula proposed by Hirschorn et al. ${ }^{14}$ and later reexamined by White et al. ${ }^{15}$ The approach assumes monotonic, nonlinear (power-law) distribution of the resistivity within the membrane where the power of this distribution is accounted for by the parameter $g$ (Equation 3). As can be seen from Equation 3. $g$ is related to the parameter $\alpha$, which is a characteristic of CPE used in modeling the frequency dependence of the membrane capacitance.

$$
\begin{gathered}
\varepsilon=\frac{L}{\varepsilon_{0}} g^{\frac{1}{\alpha}}\left(\frac{Q}{A}\right)^{\frac{1}{\alpha}}\left(L_{\rho \delta}\right)^{(1-\alpha) / \alpha} \\
g=1+2.88(1-\alpha)^{2.375}
\end{gathered}
$$

Where A is area of skin membrane $\left(0.64 \mathrm{~cm}^{2}\right), \rho_{\delta}$ rd is the resistivity at position $\delta$ perpendicular to the surface (at the dermal side of the skin membrane), L $(10 \mu \mathrm{m})$ is the assumed thickness of the main barrier, the stratum corneum (SC). The dielectric constant is related to the capacitance according to Equation 4.

$$
\varepsilon=\frac{\left(\frac{C}{A}\right) L}{\varepsilon_{0}}
$$

Where, $\varepsilon_{0}$ is the permittivity of vacuum $\left(8.8542^{\prime} 10^{-12} \mathrm{~F} / \mathrm{m}\right)$. Hence, the dielectric constant of the skin membrane is given by

$$
\varepsilon=\frac{L}{\varepsilon_{0}} g^{\frac{1}{\alpha}}\left(\frac{Q}{A}\right)^{\frac{1}{\alpha}}\left(L_{\rho \delta}\right)^{(1-\alpha) / \alpha}
$$

The lowest value of the membrane resistivity rd was assumed to be equal to the resistivity of the solution in the receptor chamber of the Franz cell.

\section{Drug penetration}

Penetration of MF through skin and silicone membranes was determined using flow-through diffusion cells ${ }^{16}$ mounted in a heat block according to the system designed by Clowes et al. ${ }^{17} \mathrm{~A}$ water bath with circulation (Techne TE-10A thermoregulator; Bibby Scientific, Staffordshire, UK) was used to keep the temperature at $32 \pm 0.3^{\circ} \mathrm{C}$. The test formulations were applied either as semi-finite dose $\left(25 \mathrm{mg} / \mathrm{cm}^{2}\right)$, resembling the set-up used in the clinical study by Berg et al. ${ }^{13}$ or as infinite dose $\left(260 \mathrm{mg} / \mathrm{cm}^{2}\right)$. When the higher dose was used the cells were also occluded with Parafilm to maintain fixed boundary conditions. Furthermore, MF has very low water solubility and degrades at $\mathrm{pH}$ values above $4.9 .{ }^{10}$ To overcome these restrictions, we decided to use isotonic $20 \mathrm{mM}$ citrate buffer ( $\mathrm{pH} 4.5$ ) mixed with $30 \%(\mathrm{v} / \mathrm{v})$ ethanol as receptor media. In this way, degradation of MF was avoided and sink conditions were maintained (addition of 30\% ethanol increased the solubility of MF to $26 \mu \mathrm{g} / \mathrm{mL}$ ). The receptor solution was continuously pumped through the cells with a flow rate of $1.5 \mathrm{~mL} / \mathrm{h}$ and collected as $3-\mathrm{mL}$ aliquots. The collected aliquots were placed in sealed glass vials and stored at $-20^{\circ} \mathrm{C}$ until analysis.

\section{Analysis}

MF was extracted from the membranes according to a procedure proposed by Şenyiğit et al. ${ }^{18}$ : The membranes were gently dried with tissue wipes and the areas which had been exposed in the diffusion cells 
$(0.64 \mathrm{c})$ were isolated within $10 \mathrm{~min}$ from terminating the experiment. MF was extracted from the membranes into $1 \mathrm{~mL}$ Acetonitrile-water mixture (60:40) by sonication for $15 \mathrm{~min}$ (Ultrasonic cleaner; VWR, IL, USA). The extraction solution was then placed in a new vial and stored at $-20^{\circ} \mathrm{C}$ until analysis.

The MF concentration in the samples (i.e. receptor media aliquots and extraction solutions) was assayed using a HPLC-UV set-up (Waters Alliance 2695 separation module). A Kromasil C18 $(250 \times 4.6 \mathrm{~mm}, 5 \mu \mathrm{m})$ was used as separation column and a Phenomex $\mathrm{C} 18(4 \times 3.0 \mathrm{~mm})$ was used as pre-column. The temperature of the columns was $30 \pm 2^{\circ} \mathrm{C}$. The mobile phase consisting of $75: 25 \mathrm{vol} \%$ Acetonitrile: water was pumped through the system with a flow rate of $1.5 \mathrm{~mL} / \mathrm{min}$. Detection of MF was performed at $\square=249 \mathrm{~nm}$ using a Waters 2487 Dual $\square$ Absorbance Detector. $100 \mu$ L of each sample was injected and MF concentrations were calculated against a calibration curve comprising 0.012-1.2 $\mu \mathrm{g} \mathrm{MF} / \mathrm{mL}$.

Statistical treatment of the data: Experiments were performed with six replicates in all cases and outlier analysis was performed on the penetration data using the box-plot method. ${ }^{19}$ The fences were set to 1.5 times the inter quartile range, below and above the first and the third quartile, respectively. Membranes with penetration data outside the fences were considered to be outliers and data generated on these membranes by the other methods were also excluded from further evaluation.

\section{Results}

\section{Verification of experimental design}

Infinite dose experiments under occluded conditions are often preferable to ascertain fixed boundary conditions and more robust results when studying skin penetration in vitro. In the current study one aim was however to compare the results to data from a previously reported clinical study ${ }^{13}$ where a relatively small dose $(25 \mathrm{mg}$ cream/ $\mathrm{cm}^{2}$ ) was used. One challenge with this small dose for in vitro studies might be to cover the membrane evenly and reproducible, which will affect the data evaluation. There is also a risk that reformulation might occur in a thin open application due to evaporation of volatile excipients. This would affect the properties of the vehicle and thereby the driving force for drug release. Therefore it was decided to start by evaluating potential differences in drug permeability from applying infinite amounts of the two creams $\left(260 \mathrm{mg} / \mathrm{cm}^{2}\right)$ under occlusion $v s$ open applications of semi-finite amounts $\left(25 \mathrm{mg} / \mathrm{cm}^{2}\right)$. Silicone membranes were used instead of skin for this particular study to minimize unwanted membrane response to the formulations.

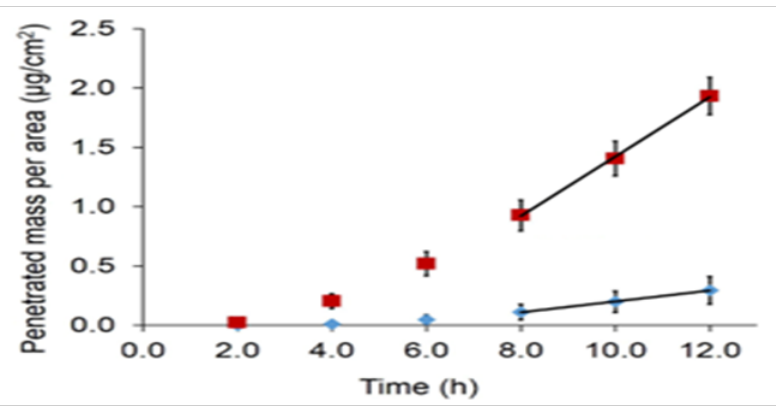

Figure I Penetration of MF through silicone membranes after application of Cream A (red squares) and Cream B (blue diamond's). Both formulations contained 0.1 wt\% MF. An infinite amount of formulation $\left(260 \mathrm{mg} / \mathrm{cm}^{2}\right)$ was applied and the cells were occluded during the experiment $(n=6$, error bars show SD).
Figure 1 shows penetration of MF through silicone membranes after application of an infinite dose of the two formulations. Interestingly, we found that the penetration rate of MF was much higher from Cream A than from Cream B. The steady state flux of MF after application of the infinite dose was $0.25 \pm 0.02 \mu \mathrm{g} / \mathrm{cm}^{2} \mathrm{~h}$ and $0.05 \pm 0.01 \mu \mathrm{g} / \mathrm{cm}^{2}$, respectively. Similar results were obtained when semi-finite doses of the two formulations were applied without occlusion during the experiment, with a steady-state flux of $0.24 \pm 0.05 \mu \mathrm{g} / \mathrm{cm}^{2} \mathrm{~h}$ for Cream A and $0.07 \pm 0.03 \mu \mathrm{g} / \mathrm{cm}^{2} \mathrm{~h}$ for Cream B. The absorbed amounts of MF in silicone were proportional to the steady state MF flux from the respective creams (Table 1). The alternative experimental conditions did however not affect the results obtained with either of these two creams. Therefore it was decided to go for infinite dose $\left(260 \mathrm{mg} / \mathrm{cm}^{2}\right)$ and occlusion in the subsequent penetration experiments with skin as the membrane.

\section{Barrier perturbation and mometasonefuorate penetration through skin}

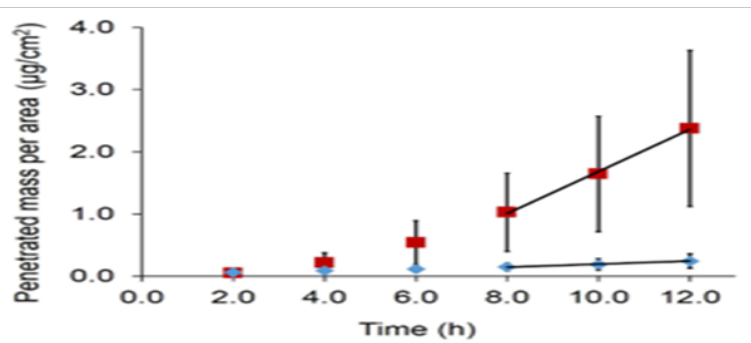

Figure 2 Penetration of MF through skin after application of Cream A (red squares) and Cream B (blue diamond's), both of which contained 0.1 wt\% MF An infinite amount of formulation $\left(260 \mathrm{mg} / \mathrm{cm}^{2}\right)$ was applied and the cells were occluded during the experiment $(n=6$, error bars show SD).

Figure 2 shows penetration of MF through skin following application of the two formulations. Similar to the results with silicone membranes, a larger amount of MF penetrated skin after application of Cream A than after application of Cream B. The steady-state flux was calculated over the interval from $6-12 \mathrm{~h}$, which gave $0.34 \pm 0.15 \mu \mathrm{g} /$ $\mathrm{cm}^{2} \mathrm{~h}$ for Cream A and $0.024 \pm 0.016 \mu \mathrm{g} / \mathrm{cm}^{2} \mathrm{~h}$ for Cream B. The ratio in steady state flux between the two formulations (A/B) did however differ when silicone and skin data were compared. The difference was significantly higher for skin, 13.9 vs 5.5 (Table 1).

In order to ensure that the observed difference between the penetration rates of MF through skin from Cream A and Cream B (Figure 2) was not due to accidental selection of more (or less) permeable membranes for one of the formulations we measured the electrical impedance of the skin membranes after terminating the penetration experiment. The steady-state flux of MF was plotted vs. the reciprocal resistance $\left(1 / R_{s}\right.$, Figure $\left.3 A\right)$ and the apparent dielectric constant e, (Figure 3B) of each membrane. After reviewing these data we may conclude that the distribution of skin membranes for studying Cream A and Cream B, respectively, did not result in a systematic difference based on impedance-derived $\mathrm{R}$ and e values. Furthermore, there was an apparent correlation between the MF steady-state flux and $e\left(R^{2} \gg 0.6-0.8\right.$, Figure $\left.3 \mathrm{~B}\right)$, while no such correlation was found between the steady state flux and $1 / \mathrm{R}_{\mathrm{s}}\left(\mathrm{R}^{2} \gg 0.2\right.$; Figure $\left.3 \mathrm{~A}\right)$.

Impedance data were also used to evaluate whether the two creams investigated affect the dielectric properties of skin membranes to different extents. Changes in the dielectric properties of skin upon application of the creams would indicate that excipients from the formulations probably interact with and alter the structure of the 
extracellular lipid matrix in the stratum corneum. ${ }^{15}$ The apparent dielectric constant measured after exposure of the membrane to the formulations $\left(\varepsilon_{\text {after }}\right)$ was therefore compared to that measured before application of the formulation $\left(\varepsilon_{\text {before }}\right)$. The resulting ratio $\varepsilon_{\text {after/before }}$ was $1.94 \pm 1.38$ for Cream A and $0.71 \pm 0.31$ for Cream B. These values indicate that Cream A has a greater tendency to increase the fluidity of the skin lipids, and thereby the diffusion of lipophilic substances such MF, than Cream B. It should however be mentioned that the absolute values of dielectric constants for skin membranes, calculated following the formalism described by Equation 2-5, are too high. This is a known problem though attempts are being made to improve interpretation of impedance data, e.g. ${ }^{15}$
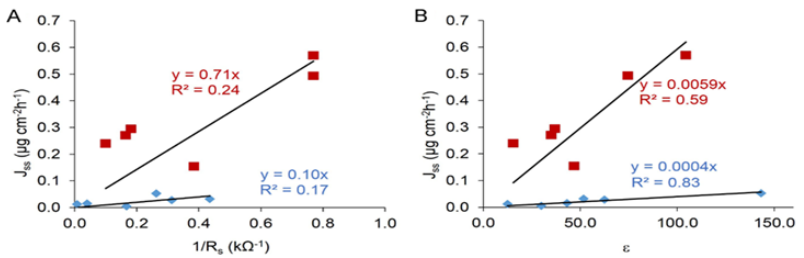

Figure 3 Skin permeability of MF plotted against skin impedance data obtained after exposure to the two creams. Steady-state flux (6 $\square$ I 2 h) vs I/ $R_{s}(A)$ and $\square$ (B) of excised skin measured after $12 \mathrm{~h}$ of exposure to Cream $A$ (red squares) or Cream B (blue diamond's) $(n=6)$.

In addition to the dielectric constant, skin resistance before and after application of the creams was compared. For Cream A, a decrease in the resistance was noted, with an $\mathrm{R}_{\text {after }} / \mathrm{R}_{\text {before }}$ ratio of $0.16 \pm 0.12$, while no significant change in resistance was seen for Cream $B\left(\mathrm{R}_{\text {after }} /\right.$ $\left.\mathrm{R}_{\text {before }}=1.14 \pm 0.93\right)$

\section{Mometasonefuorate accumulation in skin and effects of formulations wash-off}

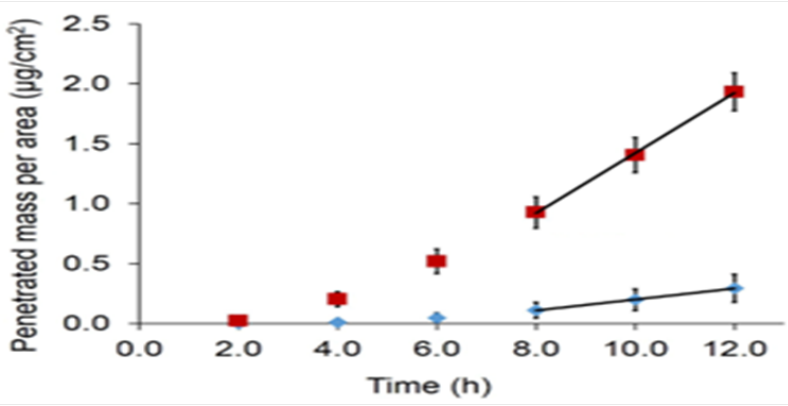

Figure 4 (A) MF release from skin after application of Cream A (red squares) and Cream B (blue diamond's). Open symbols represent the case when formulations have been removed from the skin after $6 \mathrm{~h}$ exposure, as opposed to closed symbols where skin is exposed to the formulations for the entire I2h. (B) Averaged relative drug depletion in individual membranes after removing the formulations, calculated by subtracting the release data shown in graph to the left (A) from the amount of MF absorbed in the skin after $6 \mathrm{~h}$ exposure (Table I), $(n=5 \square 6)$.

In the clinical study by Berg and co-workers ${ }^{13}$ the creams were removed $6 \mathrm{~h}$ after application and therefore it was decided to also run a penetration experiment according to this protocol. The MF release from skin after removing the creams was then followed for another $6 \mathrm{~h}$. The results are shown in Figure 4A (open symbols) and compared to data retrieved from Figure 2 where the formulations remained on the skin during the whole 12-hours experiment (filled symbols). As expected, lower amounts of MF were obtained in the receptor media in the case when Cream A had been removed from the skin surface.
There was a large difference between MF release during the last 2 hours $\left(0.17 \pm 0.09 \mu \mathrm{g} / \mathrm{cm}^{2} \mathrm{~h}\right)$ compared to the steady state flux obtained when Cream A remained on the skin $\left(J_{\mathrm{ss}}=0.34 \pm 0.15 \mu \mathrm{g} / \mathrm{cm}^{2} \mathrm{~h}\right)$. A deviation from the linear regime is also clearly visible in Figure 4A, indicating depletion of MF from the skin. For Cream B no significant change in MF release was observed from removing the formulation $\left(0.022 \pm 0.018 \mu \mathrm{g} / \mathrm{cm}^{2} \mathrm{~h}\right.$ over the last 2 hours $)$ compared to continuous exposure $\left(\mathrm{J}_{\mathrm{ss}}=0.024 \pm 0.016 \mu \mathrm{g} / \mathrm{cm}^{2} \mathrm{~h}\right)$. Figure 4B illustrates the relative decrease in individual membranes drug load after removing the creams, calculated by subtracting the release data (Figure 4A) from the amount of MF absorbed in the skin after $6 \mathrm{~h}$ exposure (Table 2).

Table 2 shows the results from extracting MF from skin after each penetration experiment. After $6 \mathrm{~h}$ application of Cream A, the skin membranes contained $1.74 \pm 1.36 \mu \mathrm{g} / \mathrm{cm}^{2} \mathrm{MF}$, while the skin membranes treated with Cream B contained $0.42 \pm 0.35 \mu \mathrm{g} / \mathrm{cm}^{2} \mathrm{MF}$ (see Table 2). No significant difference was seen when the membranes were exposed to the creams for $12 \mathrm{~h}$ instead of $6 \mathrm{~h}(2.04 \pm 0.48$ and $0.95 \pm 0.53 \mu \mathrm{g} / \mathrm{cm}^{2}$, respectively), as evaluated by the two-sided t-test with a significance level of 0.05 . This indicates that equilibrium is reached within $6 \mathrm{~h}$ exposure, which is in agreement with the observed lag time for skin-penetration (Figure 2). As shown in Figure 2, the amount of MF in skin decreased significantly during the subsequent 6h after removing Cream A (by $57 \% \pm 10 \%$, to $0.93 \pm 0.37 \mu \mathrm{g} / \mathrm{cm}^{2}$ ), while only a small decrease was seen for Cream B (by $14 \% \pm 11 \%$, to $0.62 \pm 0.19 \mu \mathrm{g} / \mathrm{cm}^{2}$,c.f. Figure 4). The ratios in absorbed amounts of MF from the two formulations (A/B) after $12 \mathrm{~h}$ were 4.3 vs 2.1 when silicone and skin data were compared (Table 1).

Table I Clinical and biochemical variables of individuals with overweightobesity

\begin{tabular}{|c|c|c|c|}
\hline & Cream A & Cream B & $\begin{array}{l}\text { Cream A/ } \\
\text { Cream B }\end{array}$ \\
\hline \multicolumn{4}{|l|}{ Silicone } \\
\hline $\mathrm{J}_{\mathrm{ss}}\left(\mu \mathrm{g} / \mathrm{cm}^{2} / \mathrm{h}\right)$ & $0.25 \pm 0.02$ & $0.046 \pm 0.014$ & 5.5 \\
\hline $\begin{array}{l}\text { Amount of } M F \text { in } \\
\text { membrane }\left(\mu g / \mathrm{cm}^{2}\right)\end{array}$ & $2.70 \pm 1.05$ & $0.63 \pm 0.12$ & 4.3 \\
\hline \multicolumn{4}{|l|}{ Skin } \\
\hline$J_{s s}\left(\mu g / \mathrm{cm}^{2} / \mathrm{h}\right)$ & $0.34 \pm 0.15$ & $0.024 \pm 0.017$ & 13.1 \\
\hline $\begin{array}{l}\text { Amount of } M F \text { in } \\
\text { membrane }\left(\mu g / \mathrm{cm}^{2}\right)\end{array}$ & $2.04 \pm 0.48$ & $0.95 \pm 0.53$ & 2.1 \\
\hline $\mathrm{e}_{\text {after }} / \mathrm{e}_{\text {before }}$ & $1.94 \pm 1.38$ & $0.7 I \pm 0.3 \mid$ & n.a. \\
\hline $\mathrm{R}_{\text {after }} / \mathrm{R}_{\text {before }}$ & 0.160 .12 & I. $14 \pm 0.93$ & n.a. \\
\hline Amount $/ \mathrm{J}_{\mathrm{ss}}$ & 6 & 40 & n.a. \\
\hline
\end{tabular}

\section{Discussion}

In the penetration experiments with silicone sheets as membranes, application of $25 \mathrm{mg} / \mathrm{cm}^{2}$ or $260 \mathrm{mg} / \mathrm{cm}^{2}$ formulation gave rise to similar MF steady-state flux. It shows that MF penetration though this membrane is not limited by the amount of formulation applied within the range investigated. When $25 \mathrm{mg} / \mathrm{cm}^{2}$ of Cream A or Cream B was applied, $18 \%$ and $4 \%$ of the MF, respectively, had penetrated after $12 \mathrm{~h}$. Thus, even in the case with $25 \mathrm{mg} / \mathrm{cm}^{2}$ formulation on silicone membranes the applied amount can be considered to be close to infinite. As the steady-state flux of MF through skin and silicone membranes is in the same order of magnitude, addition of $25 \mathrm{mg} / \mathrm{cm}^{2}$ and $260 \mathrm{mg} /$ $\mathrm{cm}^{2}$ would be expected to give similar flux on skin membranes also. 
Furthermore, when $260 \mu \mathrm{g} / \mathrm{cm}^{2}$ was applied, the formulations were occluded while no occlusion was used for $25 \mu \mathrm{g} / \mathrm{cm}^{2}$. As both setups gave similar penetration through silicone membranes, it is likely that any potential evaporation does not affect penetration through the membranes. We chose to apply $260 \mathrm{mg} / \mathrm{cm}^{2}$ of formulation on all skin membranes, in order to increase the reproducibility during application and to ensure excess MF in the donor compartment, which is important to obtain steady-state flux. Furthermore, to avoid changes in the content of the formulation due to evaporation, all skin membranes were occluded during the experiments.

Although Berg et al. ${ }^{13}$ reported equal clinical effect from using the two creams, our study has shown that Cream A gives rise to an order of magnitude higher penetration of MF through skin (Figure 2), compared to Cream B. Higher penetration of MF through stratum corneum indicates that increased systemic availability can be expected. As for all topical Glucocorticoids, the target of treatment is viable skin. Systemic availability and uptake in the blood is therefore not desirable, and could possibly lead to severe side effects such as hypothalamic-pituitary-adrenal axis suppression. ${ }^{1,7}$

There was also a slight difference between the two creams regarding the amount of MF that accumulated in skin. After a $6 \mathrm{~h}$ application, we found that the skin had absorbed $20 \times 10^{14}$ and $5 \times 10^{14} \mathrm{MF}$ molecules per $\mathrm{cm}^{2}$ from Cream A and Cream B, respectively. Smith and Shuster have previously determined that human skin contains $12 \times 10^{10}$ glucocorticoid receptors per $\mathrm{cm}^{25}$. Thus, after a $6 \mathrm{~h}$ application of either of the two creams skin contains four orders of magnitude more MF molecules than the number of available receptors. A constraint in comparing our in vitro results to clinical data is however that we ensured that sink conditions applied for the receptor media, resembling a situation where normal blood flow is maintained in vivo. Application of Glucocorticoids does generally result in vasoconstriction with reduced blood flow in the dermis and a reduced ability of molecules to be removed by the systemic circulation. It is therefore possible that higher accumulation of MF in the dermis occurs in vivo where vasoconstriction takes place.

Although a larger amount of MF accumulated in the skin from application of Cream A than of Cream B, the amount of MF in the skin was in the same order of magnitude for the two formulations (Table 2). Both formulations apparently deliver a sufficient amount of MF to the skin where the glucocorticoid receptors are located. However, the MF penetration through skin differs by an order of magnitude. The ratio between the absorbed amount of MF in skin and the steady-state flux through skin was 6 for Cream A and 40 for Cream B (Table 1). This clearly illustrates a large difference between the two formulations. Application of Cream B results in a larger relative accumulation of MF in the skin while application of Cream A results in higher penetration through the skin and faster removal of MF from the skin. Six hours after Cream A was removed, $57 \%$ of the MF accumulated in the skin had been released from the membrane (Figure 4B). For Cream B, only $14 \%$ of the MF in the skin had been released $6 \mathrm{~h}$ after removal of the cream. Furthermore, Figure 4A clearly shows a decrease in the drug penetration from removing Cream A compared to when the skin was continuously exposed to the formulation. It is evident that there is a pronounced decrease in MF in the skin after removing Cream $\mathrm{A}$ which is not seen with Cream B. These results indicate that a longer retention time of MF in the skin may be achieved with Cream B. Longer retention time is desirable, as this will not only lead to more even distribution of MF over time but-more importantly-will possibly reduce the systemic burden.
Table 2 Amount of MF accumulated in the skin membranes after application of Cream $A$ and Cream B for 6 or $12 \mathrm{~h}$ ( $n=4 \square 6$, error bars show SD)

\begin{tabular}{|c|c|c|c|}
\hline \multicolumn{2}{|l|}{ Time (h) for } & \multicolumn{2}{|c|}{$\begin{array}{l}\text { Amount MF in membrane }(\mu \mathrm{g} / \\
\left.\mathrm{cm}^{2}\right)\end{array}$} \\
\hline $\begin{array}{l}\text { Removal of } \\
\text { Cream }\end{array}$ & $\begin{array}{l}\text { Extraction } \\
\text { of MF }\end{array}$ & $\begin{array}{l}\text { Cream } \\
\text { A }\end{array}$ & Cream B \\
\hline 6 & 6 & $1.74 \pm 1.36$ & $0.42 \pm 0.35$ \\
\hline 6 & 12 & $\begin{array}{l}0.93 \pm \\
0.37\end{array}$ & $0.62 \pm 0.19$ \\
\hline 12 & 12 & $2.04 \pm 0.48$ & $0.95 \pm 0.53$ \\
\hline
\end{tabular}

Previous studies have shown a direct correlation between the reciprocal of the skin resistance and penetration of hydrophilic molecules through the skin..$^{20} \mathrm{MF}$ is, however, a very lipophilic compound $(\operatorname{lgP}=4.5)$, and therefore it is not surprising that such a correlation between penetration and skin resistance was not observed (Figure 3A). It has been suggested that non-polar lipophilic molecules penetrate the skin by diffusion through the lipid-rich parts of the skin. ${ }^{21}$ The structural features of the lipid layers in the stratum corneum are reflected by the effective dielectric constant, $\varepsilon .^{15}$ It is therefore more likely to find a correlation between the dielectric constant of the skin and the steady-state flux of MF. This is shown in Figure 3B as linear dependencies between $\mathrm{J}_{\mathrm{ss}} \& \varepsilon$, with $\mathrm{R}^{2}$ values of 0.6 and 0.8 for membranes exposed to Cream A and Cream B, respectively. A higher e value indicates that the extracellular lamellar lipid matrix in the stratum corneum has an increased fraction of lipids in the fluid state, and in many studies it has been shown that molecular diffusion in lipids is facilitated by a transition from the crystalline to the liquid crystalline state. ${ }^{22-24}$

We also compared the dielectric properties of the skin, measured before and after application of the formulations. It is clear that the two formulations affect the permeability of the skin to MF to different extents. Table 1 illustrates how Cream A and Cream B affect the penetration of MF through skin relative to silicone. For penetration through silicone membranes, the ratio between Cream A and Cream $B$ had a value of approximately five. However, when it came to skin, Cream A generated a steady-state flux that was 14 times higher than that for Cream B. This indicates that Cream A promotes the diffusion of MF in skin to a greater extent than Cream B. Because MF is a lipophilic substance, it could be expected to penetrate the skin through the lipid pathway. ${ }^{20}$ Increased diffusion would therefore be expected to correlate with increased fluidity of the skin lipids and a corresponding increase in dielectric constant. The resulting ratio $\mathrm{e}_{\text {after }} \mathrm{e}_{\text {before }}$ had a value of $0.71 \pm 0.31$ for Cream B and $1.94 \pm 1.38$ for Cream A. These values confirm that Cream A has a greater tendency to increase the fluidity of the skin lipids, and thereby the diffusion of lipophilic substances, e.g. MF in this case, than Cream B.

Furthermore, a substantial decrease in skin resistance was seen on application of Cream $A\left(R_{\text {after }} / R_{\text {before }}=0.16 \pm 0.12\right)$, which also indicated that the lipid matrix in skin became more fragmented/disturbed. For Cream B, no significant difference in resistance before and after application of the cream could be detected $\left(\mathrm{R}_{\text {after }} / \mathrm{R}_{\text {before }}=1.14 \pm 0.93\right)$. This, together with the fact that the change in e on application of Cream $\mathrm{B}$ was also not considerable, suggests that the initial structure of the skin membrane is preserved on application of Cream B. In summary, the impedance results indicate that Cream A strongly affects the lipid structures of skin membranes, which probably become more fluid and fragmented. This might be a reason for the much higher penetration of MF from Cream A than from Cream B. 


\section{Conclusion}

MF from the two creams absorbs to the same extent in excised skin, while Cream A generates an order of magnitude higher steady state drug flux through skin. In corresponding experiments with silicone sheets as membrane the ratios in absorbed amounts of MF and drug flux are similar, which is expected when neither of the creams affects the membrane. Cream A also caused a two-fold increase in the skin dielectric constant (e) and a decrease in resistance (R).The increase in e may be attributed to an increased fluidity of the extracellular lipid matrix in the stratum corneum corresponding to a higher skin permeability for lipophilic molecules like MF. No significant change in e was seen with cream B. The ratio between absorbed amount of $\mathrm{MF}$ in skin (after 12h exposure) and drug flux over skin was 6 for Cream A and 40 for Cream B. The relative depletion of MF from skin after removing the formulations was also higher in skin treated with Cream A. To conclude, Cream B appears to be the safer alternative as it does not seem to perturb the skin and imposes less systemic burden without sacrificing clinical efficacy.

\section{Acknowledgments}

Henri Hansson and Anna Karin Moren (Galenica AB) are gratefully acknowledged for fruitful discussions. We also thank Anna Nilsson (Galenica AB) for technical assistance. We are grateful to the Knowledge Foundation (KK-stiftelsen, Sweden), the Gustaf Th. Ohlsson Foundation (Sweden), and the Biofilms - R search Center for Biointerfaces at Malmo University (Sweden) for financial support.

\section{Conflicts of interest}

The author declares that there is no conflict of interest.

\section{References}

1. Prakash A, Benfield P. Topical mometasone-A review of its pharmacological properties and therapeutic use in the treatment of dermatological disorders. Drugs. 1998;55(1):145-163.

2. Bousquet J. Mometasone furoate: an effective anti-inflammatory with a well-defined safety and tolerability profile in the treatment of asthma. Int J Clin Pract. 2009;63(5):806-819.

3. R zende RM, Silveira F, Barbosa AP, et al. Objective reduction in adenoid tissue after mometasone furoate treatment. Int $J$ Pediatr Otorhinolaryngol. 2012;76(6):829-831.

4. Rossi GA, Cerasoli F, Cazzola M. Safety of inhaled cortico steroids: Room for improvement. Pulm Pharmacol Ther. 2007;20(1):23-35

5. Smith K, Shuster S. A Comparison of the Glucocorticoid R ceptors in the Dermis and Epidermis of the Rat. Clin Exp Dermatol. 1987;12(2):8992.

6. Leiferman KM, Schroeter A, Kirschner MK, et al. Characterization of the Glucocorticoid $\mathrm{R}_{\mathrm{e}}$ ceptor in Human-Skin. J Invest Dermatol. 1983;81(4):355-360

7. Wiedersberg S, Leopold CS, Guy RH. Bioavailability and bioequivalence of topical glucocorticoids. European Journal of Pharmaceutics and Biopharmaceutics. 2008;68(3):453-466.
8. Kecskes A, Heger-Mahn D, Kuhlmann RK, et al. Comparison of the Local and Systemic Side-Effects of Methylprednisolone Aceponate and Momentasone Furoate Applied as Ointments with Equal Anti inflammatory Activity. J Am Acad Dermatol. 1993;29(4):576-580.

9. Brazzini B, Pimpinelli N. New and established topical corticosteroids in dermatology: clinical pharmacology and therapeutic use. American journal of clinical dermatology. 2002;3(1):47-58.

10. Teng XW, Cutler DC, Davies NM. Degradation kinetics of mometasone furoate in aqueous systems. Int J Pharm. 2003;259(1-2):129-141.

11. Straube MD, Zesch A. Current guidelines applicable for the approval of topically applied dermatological drugs in the EU. Fundam Clin Pharmacol. 2004;18(5):503-511.

12. SWEDIS. Database for drug products on Swedish market. 2007.

13. Berg M, Svensson A, Faergemann J. A Novel Formulation of Mometasone Furoate in Psoriasis Patients: A Multicenter, Randomized, Double-Blind Clinical Study. Adv Ther. 2013;30(3):503-516.

14. Hirschorn B, Orazem ME, Tribollet B, et al. Constant-Phase-Element Behavior Caused by $\mathrm{R}$ sistivity Distributions in Films. $J$ Electrochem Soc. 2010;157(12):C452-C457.

15. White EA, Orazem ME, Bunge AL. Characterization of Damaged Skin by Impedance Spectroscopy: Chemical Damage by Dimethyl Sulfoxide. Pharm $R_{e} s .2013 ; 30(10): 2607-2624$.

16. Bronaugh RL, Stewart RF. Methods for Invitro PercutaneousAbsorption Studies IV: The Flow-through Diffusion Cell. J Pharm Sci. 1985;74(1):64-67.

17. Clowes HM, Scott RC, Heylings JR. Skin Absorption-Flow-through or Static Diffusion Cells. Toxicology in Vitro. 1994;8(4):827-830.

18. Senyigit T, Padula C, Ozer O, et al. Different approaches for improving skin accumulation of topical corticosteroids. Int J Pharm. 2009;380(12):155-160.

19. Frigge M, Hoaglin DC, Iglewicz B. Some Implementations of the Boxplot. American Statistician. 1989;43(1):50-54.

20. White EA, Horne A, Runciman J, et al. On the correlation between singlefrequency impedance measurements and human skin permeability to water. Toxicology in Vitro. 2011;25(8):2095-2104.

21. Mitragotri S. Modeling skin permeability to hydrophilic and hydrophobic solutes based on four permeation pathways. J Controlled $R_{e}$ lease. 2003;86(1):69-92.

22. Bjorklund S, Engblom J, Thuresson K, et al. A water gradient can be used to regulate drug transport across skin. $J$ Controlled $R_{e}$ lease. 2010;143(2):191-200

23. Hadgraft J. Skin deep. European Journal of Pharmaceutics and Biopharmaceutics. 2004;58:291-299.

24. Welin-Berger K, Neelissen JA, Engblom J. Physicochemical interaction of local anesthetics with lipid model systems-correlation with in vitro permeation and in vivo efficacy. J Controlled $R_{e}$ lease. 2002;81(1-2):3343. 